\title{
Opinion change as a function of perceived similarity of the communicator and subjectivity of the issue*
}

\author{
JUDSON MILLS \\ University of Maryland, College Park, Md. 20742 \\ and \\ CHARLES E. KIMBLE \\ Antioch College, Yellow Springs, Ohio 45387
}

An experiment tested the hypothesis that the more subjective the audience thinks the issue of the communication is, the greater will be the relative effectiveness of a communicator they think is similar to themselves compared to a communicator they think is dissimilar. College women ranked poetry after inspecting rankings attributed to another girl. They were led to believe that rankings of the poetry were either a matter of taste (subjective issue) or artistic knowledge (objective issue) and that the other was either similar or dissimilar to themselves. On a measure of agreement with the other's rankings, a significant interaction was found between whether the other was similar or dissimilar and whether the issue was subjective or objective, as predicted by the hypothesis.

In their discussion of communicator credibility, Hovland, Janis, \& Kelly (1953) made the following suggestion. "In certain matters persons similar to the recipient of influence may be considered more expert than persons different from him. An individual is likely to feel that persons with status, values, interests, and needs similar to his own see things as he does and judge them from the same point of view. Because of this, their assertions about matters of which the individual is ignorant but where he feels the viewpoint makes a difference (e.g., about the satisfaction of a given job or the attractiveness of some personality) will tend to carry special credibility [p. 22]."

It is reasonable to suppose that people will feel that the particular viewpoint makes a difference when the issue is a subjective one, when there is a great deal of disagreement about the issue. Thus, it might be expected that when the audience thinks that the issue is subjective, the effectiveness of a communicator they think is similar to themselves will be relatively greater.

An experiment was designed to test the hypothesis that the more subjective the audience thinks the issue of the communication is, the greater will be the relative effectiveness of a communicator they think is similar to themselves compared to a communicator they think is dissimilar.

\section{METHOD}

Under the guise of a study of impression formation, college females ranked passages of poetry after inspecting the rankings supposedly made by another girl. Agreement with the other girl's

*This study was supported by a grant from the National Science Foundation. rankings was measured under four different conditions: subjective-similar, subjective-dissimilar, objective-similar, and objective-dissimilar. In the subjective conditions, the Ss were led to believe that rankings of the poetry were a matter of personal taste, and in the objective conditions, that the rankings were a matter of artistic knowledge. In the similar conditions, the Ss were given information about the other indicating that she was similar to themselves; in the dissimilar conditions, they were given information indicating that the other was dissimilar.

The Ss were 203 women in introductory psychology at the University of Texas, Austin, who participated in the experiment as part of a course requirement. They were run in 15 sessions. Within each session, Ss were assigned randomly to the four experimental conditions with as near to equal number as possible in each condition.

When Ss arrived at the experimental room, they were directed to previously assigned seats. The $\mathrm{E}$ introduced the experiment as a study concerned with impression formation. He told the Ss that each of them would receive a booklet containing two forms filled out by a girl in another class, an occupational interests and attitudes inventory and a reactions to poetry sheet. Their task was to read the two forms the other girl had filled out and to form a global impression of her. Later they would be asked to give their impressions by rating her on a number of characteristics.

The occupational interests and attitudes inventory consisted of 38 true-false items taken from the masculinity-femininity scale of the California Personality Inventory (Gough, 1969) that had been filled out by the Ss at the beginning of the semester. For Ss in the similar conditions, the answers for 34 of the 38 items were exactly the same as the answers that the $S$ had given earlier. For Ss in the dissimilar conditions, the answers for the 34 items were exactly opposite to the answers that the $\mathrm{S}$ had given earlier. For all Ss, four extremely masculine items were always marked false (for example, "I would like to be a soldier").

The reactions to poetry sheet contained 12 two-line stanzas of poetry. The instructions stated that these poetic passages were evaluated by a number of leading poets and poetry critics. For Ss in the subjective conditions, the instructions continued: "The poetry experts did not agree in their rankings of the artistic quality of the passages. When the experts were asked if reactions to the passages were a matter of taste or whether there were objective differences in the passages, they agreed that reactions to them were a matter of personal taste and not a matter of artistic knowledge." For Ss in the objective conditions, the instructions continued: "The poetry experts agreed very well in their rankings of artistic quality of the passages. When the experts were asked if reactions to the passages were a matter of taste or whether there were objective differences in the passages, they agreed that reactions to them were a matter of artistic knowledge and not a matter of personal taste." The rankings of the artistic quality of 12 passages were the same in all conditions and had been chosen randomly.

When the Ss had finished studying the material supposedly filled out by the other girl, the $E$ mentioned that before they gave their impressions of her, one other thing was needed. He needed to have them fill out the blank reactions to poetry sheet which appeared in their booklets "so that we can control for whatever effect your reactions to the poetry may have on your impressions of the other girl." Five girls who gave the same rank to more than one passage were not included as Ss.

After the Ss had ranked the poems, they were instructed to give their impressions of the other girl by indicating on a form in their booklets. on a scale from 0 (extremely inappropriate) to 20 (extremely appropriate). how well different characteristics 
Table 1

Means for the Measure of Agreement With the Other

\begin{tabular}{lllll}
\hline & \multicolumn{4}{c}{ Other } \\
\cline { 2 - 5 } \multicolumn{1}{c}{ Issue } & \multicolumn{2}{c}{ Similar } & \multicolumn{2}{c}{ Dissimilar } \\
\hline Subjective & 37.0 & $(50)$ & 40.7 & $(52)$ \\
Objective & 40.0 & $(50)$ & 36.7 & $(51)$ \\
\hline
\end{tabular}

Note-The lower the score, the greater the agreement with the other. Ns given in parentheses.

applied to the girl. The characteristics were: artistic, attractive, competent, cold, earnest, expert, friendly, frank, knowledgeable, likable, unpleasant. The form also contained the question, "How similar to you is the person?" which was answered on a scale from 0 (extremely dissimilar) to 20 (extremely similar). The Ss were assured that their ratings would be kept strictly confidential.

After the Ss had finished rating the other girl, the E asked them to write a few sentences on the back describing their reactions to the study, emphasizing that they could say anything they wanted to about the study. The comments of 12 girls indicated suspicion about the procedure, and they were not included as Ss. Finally, before dismissing the Ss, the E explained the necessity of their not discussing the experiment with anyone.

\section{RESULTS AND DISCUSSION}

The Ss' answers to the question, "How similar to you is the person?" provide evidence about the effectiveness of the similarity manipulation. The mean for the answers to this question was 15.8 for the similar conditions and 4.7 for the dissimilar conditions. The difference was highly significant $(\mathrm{F}=520.76, \mathrm{df}=1 / 199)$. Neither the main effect of subjectivity of the issue nor the interaction approached significance. The results indicate that the similarity manipulation was highly effective.

For every one of the characteristics that were rated, there was a significant difference between the similar and dissimilar conditions. In the similar conditions, the other was rated as more artistic, more attractive, more confident, less cold, more expert, more friendly, more frank, more knowledgeable, more earnest, more likeable, and less unpleasant than in the dissimilar conditions. All of these differences were significant beyond at least the .02 level. In addition to varying similarity, the similarity manipulation produced differences in liking for the other. The other was liked more in the similar conditions than in the dissimilar conditions.

There was only one other significant difference for the ratings of the various characteristics. The other was rated as more cold in the objective conditions than in the subjective conditions $(\mathrm{p}<.05)$. For none of the characteristics was the interaction between the subjectivity of the issue and the similarity of the other significant at the .05 level.
From the hypothesis that the more subjective the issue, the greater will be the relative effectiveness of a similar communicator, it would be expected that the difference in agreement with the similar and dissimilar others would be more strongly in favor of the similar other under the subjective condition than under the objective condition. That is, the hypothesis predicts an interaction between similarity and subjectivity of the issue. A measure of agreement with the other was calculated for each $\mathrm{S}$ by summing the absolute difference for each poetry passage between the rank supposedly given by the other and rank given by the $\mathrm{S}$. The means for the measure of agreement with the other for the four experimental conditions are presented in Table 1.

As can be seen from Table 1, the results are in line with the hypothesis. Agreement with the other was greater in the subjective-similar than in the subjective-dissimilar condition, while agreement with the other was less in the objective-similar than in the objective-dissimilar condition. The interaction between similarity of the other and subjectivity of the issue was significant at the .05 level $(F=5.11, d f=1 / 199)$. Neither of the main effects approached significance. The difference between the subjective-similar and subjective-dissimilar conditions was not significant; neither was the difference between the objective-similar and objective-dissimilar conditions. Perhaps it should be pointed out that the hypothesis does not make any specific predictions about the main effects of similarity or subjectivity of the issue or about differences between individual conditions.

The significant interaction between similarity and subjectivity provides support for the hypothesis that the more subjective the audience thinks the issue of the communication is, the greater will be the relative effectiveness of a communicator they think is similar to themselves compared to a communicator they think is dissimilar. This hypothesis was based on the assumptions that a similar person will be considered more expert than a dissimilar person to the extent to which the viewpoint makes a difference and that the viewpoint will be regarded as making a greater difference, the more subjective the issue is perceived to be.

\section{REFERENCES}

Gough, H. G. California Personality Inventory. Palo Alto: Consulting Psychologists Press, 1969.

Hovland, C. I., Janis, I. L., \& Kelly, H. H. Communication and persuasion. New Haven: Yale University Press, 1953.

(Received for publication A pril 26, 1973.) 